\title{
PACIENTE HOSPITALIZADO - ATUAÇÃO DA ENFERMEIRA NA PREVENÇÃO DE LIMITAÇõES FÍSICAS
}

\author{
Marlúcia Nunes Comarú*
}

\begin{tabular}{|l|l|} 
& $\mathrm{RBEn} / 04$ \\
\hline
\end{tabular}

COMARƯ, M.N. - Paciente hospitalizado - Atuação da Enfermeira na prevenção de limitações físicas. Rev. Bras. Enf.; RJ, $28: 22-29,1975$.

\section{I - INTRODUÇÃO}

Segundo Kamiyama (6) "é da responsabilidade da enfermeira explicar os cuidados administrados, esclarecer dúvidas sobre a doença e tratamento, medicação, exames, ocorrências inesperadas no plano assistencial (suspensão de exames, tratamentos ou mesmo da operação) dentro dos limites impostos pela ética, responsabilidade profissional, potencialidade do paciente e respeitando-se sua área de trabalho na equipe de saúde multiprofissional".

Encontramos nas palavras acima, a afirmativa de alguns aspectos de enfermagem que no momento muito nos preocupam, quais sejam, cuidados especiais para a prevenção das limitações físicas decorrentes da hospitalização do paciente.

É da mesma autora, a afirmativa de que as expectativas do paciente são relativas às informações e orientações sobre a assistência que lhe é dispensada durante o tratamento. $\dot{E}$ interessante observar que as expectativas do paciente estão intimamente relacionadas com uma das responsabilidades profissionais da enfermeira, isto é, o esclarecimento sobre os seus cuidados. Como a expectativa do paciente com relação à enfermeira coincide com a atuação que dela se espera, pensamos focalizar nesta oportunidade, alguns aspectos relacionados à prevenção de limitações físicas, que, se levados em consideração, poderão contribuir para satisfazer as expectativas do paciente e dar à enfermeira, a satisfação de atuar na mesma direção.

É portanto, nosso objetivo neste trabalho, demonstrar que a aplicação dos princípios de mecânica corporal, de mobiłização do paciente no leito e da realização de movimentação passiva e ativa, são os meios utilizados para prevenir as limitações físicas que podem ocorrer quando o paciente permanece acamado.

\section{II - PACIENTE HOSPITALIZADO}

Una das formas de avaliação da qua-

* Diretora do Serviço de Enfermagem da Divisão de Reabilitação Profissional de Verguero do Haspital das Clíncas - F.M.U.S.P. 
COMARÚ, M.N. - Paciente hospitalizado - Atuação da Enfermeira na prevenção de limitaçōes físicas. Rev. Bras. Enf.; RJ, 28 : 22-29, 1975.

lidade da assistência de enfermagem prestada ao paciente hospitalizado acamado, relaciona-se às limitações físicas instaladas durante este período.

Para a enfermeira corresponder à responsabilidade assumida e às expectativas do paciente, ela deve primordialmente:

- ter conhecimento da doença - incluindo o tratamento e o prognóstico médico;

- relacionar-se com o paciente de modo a facilitar a interação enfermeirapaciente, e por conseguinte identificar as necessidades individuais do seu paciente - como pessoa e como portador de determinados problemas de ordem física;

- manter comunicação constante com os demais membros da equipe de saúde, com vistas ao atendimento das necessidades identificadas;

- aplicar princípios e utilizar-se de meios que permitam a prevenção de limitações físicas.

Sabe-se que a doença pode predispor 0 paciente a atitude de passividade. Esta pode ser considerada sob dois aspectos: atitude de "entrega", de aceitação total de tudo que lhe acontece, ou então de passividade física, por impossibilidade de mover-se. Colocados estes dois aspectos, e sabendo que a falta de uso de um órgão ou de uma parte do corpo acarreta alterações, podendo levar à limitações funcionais, parece-nos conveniente abordar o problema do ponto de vista da assistência de enfermagem.

Para melhor fundamentar a atuação da enfermeira transcrevemos o conceito de enfermagem, segundo Horta (4):

"Enfermagem é a ciência e a arte de assistir o ser humano (indivíduo, família e comunidade) no atendimento de suas necessidades básicas, de torná-lo independente desta assistência, quando possível, pelo ensino do auto-cuidado; de recuperar, manter e promover a saúde em colaboração com outros profissionais.
Assistir em enfermagem é: fazer pelo ser humano aquilo que ele não pode fazer por si mesmo; ajudar ou auxiliar quando parcialmente impossibilitado de se auto-cuidar; orientar ou ensinar, supervisionar e encaminhar a outros profissionais".

Uma vez conceituada a enfermagem, podemos abordar algumas conseqüências do repouso para os vários sistemas corporais e a atuação da enfermeira na prevenção de limitações físicas a que o paciente está sujeito.

\section{III - SISTEMAS CORPORAIS}

1 - Sistema Músculo-Esquelético - A restrição de movimentação, imposta pelo tratamento - mesmo em pessoas hígidas, porém com limitação temporária do sistema locomotor - pode levar a distrofia, perda da tonicidade muscular e diminuição da força muscular; os efeitos podem ser comprovados, quando se verifica que o paciente em convalescença, não consegue manter-se ereto sem auxílio. Concomitantemente poderá estar presente a dor articular, o que freqüentemente impede a realização dos demais movimentos.

Devido à tensão exagerada de determinados grupos musculares, em contraposição com seus antagonistas continuamente relaxados, o paciente às vezes assume posição de permanente flexão de certas articulações (às vezes pode ocorrer posição viciosa por defesa à dor), vindo a permitir o desenvolvimento da contratura em flexão.

É importante ressaltar, que não raro, após encerrado o tratamento, verifica-se a presença de sequelas que impedem a realização de certos movimentos articulares, tornando o indivíduo - agora sadio - incapaz para realizar determinados tipos de atividades. Ocorreu portanto, durante o período de repouso, a instalação de limitações físicas, conseqüentes de posição viciosa e estado de 
COMARÚ, M.N. - Paciente hospitalizado - Atuação da Enfermeira na prevenção de limitações físicas. IRev. Bras. Enf.; RJ, 28 : 22-29, 1975.

relaxamento no leito. Colocado desta forma, pode-se dizer, que o paciente, por causa das perdas sofridas, tornou-se incapacitado e portanto dependente.

Dentro da conceituação da Enfermagem ...."de torná-lo independente desta assistência...; de recuperar, manter e promover a saúde...", e respeitando aspectos da doença, do tratamento que está sendo realizado e do prognóstico médico, a enfermeira poderia elaborar o seu plano de assistência, no qual constaria:

- mudança frequente de decúbito, proporcionando apoios adequados nas regiões que estiverem com musculatura enfraquecida e que, portanto, possam levar à posição viciosa e defeito postural.

$\mathrm{Na}$ posição dorsal, por exemplo, os músculos rotadores externos da coxo-femural, sendo mais potentes que seus antagonistas, proporcionam permanente rotação dos membros inferiores; a colocação de coxim firme, lateralmente sob a coxa, desde a altura da crista ilíaca até o terço inferior da coxa, mantém o membro em posição anatômica;

- para permitir relaxamento dos extensores da coxa e dos joelhos, coloca-se coxim com cerca de $5 \mathrm{~cm}$ de expessura desde o terço inferior da coxa até o terço inferior da perna, deixando os calcâneos livres; a funcionalidade do pé depende da manutenção do equilíbrio entre os músculos responsáveis pela flexão plantar e dorsal e pela inversão e eversão; sendo os músculos flexores dorsais dos pés mais fracos que os seus antagonistas, os flexores plantais - e os principais, dentre estes, se inserem no tendão de Aquiles - há tendência para equinismo. Para prevenir esta deformidade, aconselha-se o uso de suporte plantar articulado; para manter o equilíbrio da tensão dos músculos envolvidos, solicita-se ao paciente, que através de movimentos coordenados, empurre o suporte, estimulando desta forma a ação muscular.
- para que os membros superiores permaneçam em posição funcional e com os músculos sob a menor tensão possível, deve-se colocar o braço em leve abdução e rotação interna, o antebraço em supinação e o cotovelo em leve flexão;

- a mão espalmada sobre o leito pode levar a limitação das articulações do punho e das falanges; para evitar que isto ucorra, coloca-se a mão do paciente em posição de quem segura uma garrafa e para manter esta posição, ajusta-se um perzueno rcilo macio, porém firme, proporcionando flexão das falanges e oponência do polegar.

Colocado o paciente nos demais decúbitos, o primeiro fator a considerar, é que "o alinhamento das partes do corpo deve estar equilibrado e não devem fazer esforço on tensão muscular desnecessários"(9). Portanto, em decúbito ventral, a püstura correta é a que mais se aproxima da posição ereta, estando o paciente com a cabeça rodada para um dos lados. A utilização de coxins e travesseiros macios e firmes, será o recurso adicional para manter o corpo relaxado e em posição funcional no leito. Pode-se colocar um pequeno coxim sob o abdômen proporcionando relaxamento dos extensires co quadril; um travesseiro ou coxim desde o terço superior até o terço inferior da perna mantém relaxados os músculos extensores do joelho e flexores do pé.

Quando em decúbito lateral, os mesmos princípios de equilíbrio de tensão muscular devem ser observados: usandose coxim de apoio sob a cabeça, para manter o alinhamento da coluna cervical, pode-se conseguir relaxamento dos músculos trapézio e externocleidomastoideo; mantendo-se os membros superiores próximos da linha mediana e em posição funcional - flexão dos antebraços em torno de $90^{\circ}$, dorsi-flexão dos punhos e flexão das falanges - proporciona-se repouso aos músculos envolvidos; a coluna dorso-lombar pode ser 
COMARÚ, M.N. - Paciente hospitalizado -- Atuação da Enfermeira na prevenção de limitações fisicas. Rev. Bras. Enf.; RJ, 28 : 22-29, 1975.

mantida em posição neutra, através de apoio desde a região inter-escapular até a sacra; as articulações coxo-femurais e dos joelhos devem ser mantidas flexionadas, pelas mesmas razões, e um travesseiro macio e firme suportará o membro que estiver do lado oposto ao do colchão, evitando-se assim, a ação dos adutores da coxa sobre os abdutores seus antagonistas.

É importante lembrar, que nos vários decúbitos, deve-se proporcionar variação ncs ângulos articulares com o objetivo de manter a amplitude de movimentos. Estando o paciente em decúbito dorsal, colocando-o durante alguns minutos com os membros em abdução, estamos proporcionando relaxamento aos músculos adutores.

Para manutenção da tonicidade muscular e da mobilidade articular, deve-se proporcionar ao paciente movimentação passiva pelo menos uma vez ao dia. Naturalmente isto pode ser conseguido durante o banho no leito, quando é possível associar o objetivo relacionado à higiene corporal, com o de manutenção da funcionalidade do sistema músculo-esquelético. A movimentação ativa pode ser conseguida, através do auto-cuidado, o que é de fundamental importância, pois nesta oprotunidade o paciente utiliza mais o seu sistema músculo-esqulético; enquanto lava e seca a sua face, serve-se de alimentos, penteia seus cabelos, veste suas roupas, ele estará executando movimentos de abdução, adução, rotação interna e externa, flexão e extensão das articulações escápulo-umerais; estará realizando flexão, extensão, supinação e pronoção dos cotovelos e dos punhos; flexão, extensão, abdução e adução dos dedos, além do movimento de pinça do polegar. Para alcançar as extremidades inferiores - lavar os pés - ele estará executando flexão, extensão e rotação da coluna cervical e dorsolombar; fará flexão, extensão, rotação interna e externa, abdução e adução da coxo-femural, flexão e extensão dos joelhos, extensão, flexão, eversão e inversão da articulação tíbio-társica e flexão e extensão dos artelhos.

Dentre outras vantagens para o paciente, este tipo de atendimento, aparentemente sem importância, proporciona: estímulo da mobilidade articular e da tonicidade muscuiar, favorece a observação de sinaiss e sintomas; facilita a identificação de necessidades, uma vez que o contato enfermeira-paciente é mais constante. Como resultado imediato pode-se ainda verificar que a enfermeira tem oportunidade de corresponder às expectativas do paciente e ao mesmo tempo ampliar o seu campo de ação.

2 - Sistema Cárdio-Vascular - Da mesma forma que a flexão prolongada ras articulações coxo-fe:nurais e dos joelhos é prejudicial pelo fato de comprometer a amplitude articular, ela também altera a nutrição das células dos membros inferiores. O estado de relaxamento muscular proporciona um certo grau de estase venosa, que é agravada pela posição constante de flexão exagerada dos joelhos e das coxo-femurais, podend; desenvolver um processo de trombose venosa, de efeito às vezes muito sério para o paciente. "Uma teoria de flebstrombose é que esta pode so iniciar on: o dano eniotelial, causarilo velo peso do membro inferior sobre o leito, comprimindo a rantorrilha".(1)

Esta colocação leva a conc'uir que unıa das causas determinantes da fleiotrombose é a pressão; pressão esta decorrente de duas forças: "força de compressão - é a pressão vertical que c peso do corpo exerce sobre os tecides através das proeminências ósseas, enquanto estão sofrendo a força de opcsição da superfície sobre a qual está apoiada"; e "força mútua é a ação exercicia entre as superfícies contínuas do corpo, causada pela força aplicada externamente", conforme citação de Comarú e 
COMARÚ, M.N. -- Paciente hospitalizado - Atuação da Enfermeira na prevenção de limitações físicas. Rev. Bras. Enf.; Ru, 28 : 22-29, 1975.

Camargo (2). Ocorre porém, que a pressão também é apontada como uma das causas das escaras de decúbito, o que muitas vezes é um desafio para a assistência de enfermagem ao paciente acamado. Avaliando as consequências das escaras, temos que reconhecer que elas influem na instalação de limitações físicas, uma vez que, para serem tratadas, aumentam o tempo de permanência do paciente no leito. Quantas vezes o paciente já poderia ser considerado no grau 1 de dependência de enfermagem. e permanece nos graus 2, 3 ou mesmo 4, em razão das escaras de decúbito?

Salientados estes dois problemas originados pela pressão, nossa proposta imediata é que a mudança de decúbito a espaços regulares e frequentes, seja incluída nos planos de assistência de enfermagom Eiste, é um dos recursos que se deve utilizar consciente e sistematicamente, para proteger o paciente contra os danos secundários à hospitalização.

3 - Sistema Respiratório - A condição de passividade do paciente no leito condiciona a frequência respiratória a se manter regular e superficial; isto significa repnuso para algumas regiões pulmonares, fator predisponente de processos inflamatórios do sistema respiratório. Estes, são potencialmente mais graves, em se tratando de pacientes cuja terapêutica médica impõe a manutenção do corpo em uma única posição, caso típico de tratamento conservador das fraturastração óssea. Este fator, aliado à idade e/ou ao hábito do tabagismo, favorece a coleção de secreção brônquica, com estagnação nas bases e tendência a evoluir para processo pneumônico.

Uma vez considerados estes aspectos condicionantes de comprometimento respiratório, cabe a enfermeira providenciar meios de proteção para o paciente sob sua responsabilidade.

E'a pode solicitar ao paciente que se mobilize ao máximo - caso possa fazê- lo sozinho - ou providenciar para que sua posição seja modificada com a máxima frequência possível. Na posição de Fowler por exemplo, a expansão pulmonar é melhorada, graças ao relaxamento da musculatura abdominal.

Pode-se lançar mão de meios auxiliares que proporcionam um aumento da amplitude respiratória, e portanto, da capacidade vital, quais sejam: encher balões, soprar "língua de sogra", cantar (enquanto não interferir com o repouso dos demais pacientes da enfermaria), inspirar profundamente e contar números (expirando lentamente), tossir ou realizar movimentos respiratórios assistidos. E interessante notar que, motivando os pacientes de uma enfermaria, eles podem realizar em grupo essas atividades, deixando que um deles assuma o papel de líder e passe a incentivar os demais. O benefício deste tipo de assistência não se limita aos execícios respiratórios, uma vez que pode desenvolver interesse mútuo entre os pacientes, ao mesmo tempo em que se promove uma atividades recreativa. É evidente que o paciente cuja capacidade vital é preservada está sendo beneficiado, uma vez que tem condições para recuperação mais imediata. Consequentemente, ele poderá deixar o leito em tempo mais precoce e estará menos condicionado às limitações físicas decorrentes da imobilidade.

4 - Sistema Excretor - A expoliação do cálcio ósseo e sua drenagem através dos rins, favorece a formação de cálculos renais ou vesicais; este problema pode ser agravado pela baixa ingestão de líquidos, uma vez que o paciente habitualmente só se hidrata espontaneamente quando sente sede. Embora baseadas em observação assistemática, parece-nos que uma das causas da baixa ingestão hídrica pelo paciente, é a preocupação com a eliminação. A utilização da comadre ou do papagaio inibe muito o pa- 
COMARÚ, M.N. - Paciente hospitalizado - Atuação da Enfermeira na prevenção de limitações físicas. Rev. Bras. Enf.; RJ, 28 : 22-29, 1975.

ciente, pelo fato de ser esta uma das áreas de dependência do pessoal de enfermagem; por outro lado, muitas vezes não é possível elevar a cabeceira da cama, o que dificulta a ação dos músculos abdominais para compressão do baixo ventre. Outro problema sério de eliminação vesical é a incontinência, especialmente no paciente idoso. É muito comum no entanto, verificar-se que este tipo de paciente não é incontinente, mas sim tem uma capacidade vesical limitada e não consegue conter a urina, senão por pequeno espaço de tempo.

Outra situação que merece atenção especial é a presença de retenção urinária, comumente observada nos pacientes pós operados ,nos neurológicos e naqueles que receberam grande quantidade de líquido cm pouco espaço de tempo. Ocorre porém que a super distensão pode causar lesões permanentes à musculatura vesical, o que, aliado ao resíduo urinário, favorece o desenvolvimento de infecção do trato urinário.

É conveniente lembrar, que muitas vezes o paciente pode apresentar uma super-distensão não identificada pelo pesscal de enfermagem, e a eliminação se faz por transbordamento frequente do excesso de urina, o que pode ser erroneamente interpretado como polaquiúria.

Como medidas preventivas da problemática vesical no paciente acamado, ressaltamos: hidratação, oferecimento antecipado de comadre ou papagaio, verificação do volume abdominal do paciente, observação da quantidade, frequência e aspecto da eliminação, posição favorável à ação da gravidade no momento do esvaziamento e mudança contínua de posição, para prevenir estase de urina na pelve renal.

5 - Sistema Gástro-Intestinal - $\mathrm{O}$ trato alimentar do paciente acamado também está sujeito aos efeitos do repouso, uma vez que podem ocorrer distúrbios digestivos, inapetência e consti- pação intestinal. Já nos primeiros dias de repouso, podem ocorrer leves distúrbios gástricos, além da inapetência que é muito comum Repetem-se aqui. os mesmos motivos de preocupação para o paciente: ser dependente para a eliminação intestinal, principalmente quando $€ \mathrm{~m}$ ambiente coletivo. Com o intuito de restringir ح uso da comadre, alguns paciente, dirninuem as suas refeições e/ou inibem o reflexo de evacuação. A consequência imediata é a constipação intestinal que, tem como causas: ausência ou redução dos movimentos musculares, mudança de ambiente, mudança de hábitos alimentares e de eliminação A posição do paciente sobre a comadre, não favorece a ação dos músculos abdominais e ação da gravidade. Aconselhase no momento de eliminação, além das medidas tradicionais de ordem psicológica, proporcionar melhores condições físicas ao paciente, através de: elevação (se possível) da cabeceira da cama, colocação do travesseiro em posição longitudinal. desde a região lombar até à cabeça, flexão das articulações coxo-femurais e dos joelhos, e orientação para que o paciente execute respiração abdominal.

A utilização de medicamentos para ajudar o esvaziamento intestinal, pode condicionar o paciente a estímulos artificiais, que na sua vida futura poderá interferir no funcionamento orgânico.

Por último, podemos mencionar os efeitos desfavoráveis do repouso prolongado, sobre o relacionamento do paciente com o meio ambiente. Se não existe estímulo suficiente, a motivação do paciente - principalmente o de mais idade - desaparece, e sua reação se limita a uma vida quase vegetativa, enquanto as horas de sono superam em muito às necessidades normais. Enquanto dorme assume atitudes viciosas, seu desligamento aumenta e o paciente pode involuir em termos de dependência de enfermagem. 
COMARƯ, M.N. - Paciente hospitalizado - Atuação da Enfermeira na prevenção de limitaçōes físicas. Rcv. Bras. Enf.; RJ, 28 : 22-29, 1975.

Após o levantamento de todas essas necessidades do paciente e das proposições para o respectivo atendimento, evidentemente surgem perguntas gerais por parte das enfermeiras: Quem aplicará? Como aplicará, se o pessoal é insuficiente?

Rea.mente. a solução não é tão fácil como gostaríamos, uma vez que, conforme Ribeiro (10): “o pessoal de enfermagem hospitalar no Brasil era (1957) e ainda é, constituído de $70,8 \%$ de atendentes, $19,3 \%$ de auxiliar de enfermagem e $9,9 \%$ de enfermeiras". A resposta imediata, após verificação da realidade dos nossos hospitais, não seria tã̃o animadora, mas quantas vezes nós nos habituamos a uma rotina e não conseguimos parar e analisar sobre a realidade que nos cerca? E a realidade, são os leitos ocupados por indivíduos de idades as mais variadas que, enquanto realizam uma terapêutica médica, assumem pcsições viciosas, ficam inativos, passivos. esperando o dia da alta hospitalar. É necessário reconhecer que "os músculos que mantém o corpo ereto ou intervem na locomoção; perdem seu tônus com muita rapidez quando permanecem inativos. (0)

Diante das duas realidades expostas, encontra-se a enfermeira, que, consciente da sua responsabilidade procurará encontrar a solução adequada à problemática levantada. A congregação de esforços do pessoal hospitalar, liderado pela enfermeira, talvez seja a única fórmula a ser aplicada. É necessário uma firme tomada de posição, não só tendo em vista a assistência curativa mas também proporcionar assistência preventiva para evitar que, por deixar de receber este tipo de atendimento, precise o paciente recorrer à assistência de outros profissionais para corrigir limitações adquiridas durante a hospitalização. Assu- mindo a responsabilidade deste aspecto e atuando apropriadamente, pode-se também evitar que aconteça "o problema da interferência de outras profissões nas decisões que nos cabem de direito, pois que de fato não exercemos o pocier". Os programas de treinamento devem também ser utilizados para alertar o pessoal quanto às consequências do desuso cie determinadas partes do corpo. E necessário prevenir as limitações físicas, não somente participar da terapêutica médica. Quando o paciente recebe alta, é de se esperar que ele volte a realizar tudo que realizava antes, que reassuma a sua posição no trabalho, no lar. na sociedade. E para que isto ocorra, é necessário motivar e preparar o pessoal de enfermagem para atuar de forma a corresponder às expectativas do paciente e assistí-lo nas suas necessidades.

\section{IV - CONCLUSÃO}

Um dos objetivos da assistência de enfermagem ao paciente durante a terapêutica médica, deve ser a manutenção da funcionalidade, com vistas à prevenção de perdas futuras.

Através da aplicação dos princípios de mecânica corporal, da mudança sistemática da posição do paciente no leito e da realização de movimentação passiva e ativa pode-se prevenir deformidades que impõem limitações ao indivíduo para realizar determinadas atividades.

Concluimos portanto, que a prevenção de limitações físicas é uma das importantes responsabilidades da enfermeira em virtude de seu preparo profissiona! e a ela compete identificar as necessiciades do paciente nesta área, e provicenciar meios para que o pessoal de enfermagem possa atendê-lo adequadamente. 
COMARÚ, M.N. - Paciente hospitalizado - Atuação da Enfermeira na prevenção de limitações físicas. Rev. Bras. Enf.; RJ, 28 : 22-29, 1975.

\section{BIBLIOGRAFIA}

1. ASHER, R. A. d. The Dangers of going to bed. Boston, Boston University School of Nursing, 1957. Mimeografado.

2. COMARÚ, M. N. e CAMtARGO, C. A. Um problema de Enfermagem -as escaras de decúbito. Rev. Brasileira de Enfeimagem, Rio de Janeiro, 24 (6) : 96-106, out/dez, 1971.

3. HORTA, W. A. O processo de enfermagem - fundamentação e aplicação. Rev. Enfermagem em Novas Dimensões, São Paulo, 1 (1): 10-15, mar/abr, 1975.

4. HORTA, W. A. Da necessidade de se conceituar Enfermagem. Rev. Enfermagem em Novas Dimensões, São Paulo, 1 (1) : 5-7, mar/abr, 1975.

5. JOHNSTON, D. F. Total patient care. $2 .^{a}$ ed. Saint I_nuis, The C. V. Mosby Company, 1972
6. KAMIYAMA, Y. O doente hospitalizado e sua percepção quanto à prioridade de seus prob'emas. Tese de Doutoramento Escola de Enfermagem da Universidade de São Paulo, $19 \% 2$.

7. LARSON, B. C. \& GOULD, M. Ortopedic Nursing, $8 .^{a}$ ed. Saint Louis, The C. V. Mosby Company, 1970.

3. MORRISSEY, B. A. Rehabilitation Nursing, $1 .^{\mathrm{a}}$ ed. New York, G. P. Putnam's Sors, 1951.

9. NORDMARK, T. M. \& ROHWEDER, W. A. Principios científicos aplicados a la enfermeria. 1. ${ }^{a}$ ed. México, la Prensa Médica Mexicana, 1967.

10. RIBEIRO, C. M. Novas tendências no ensino e na prática da enfermagem. Rev. rla Escola de Enfermagem da USP, 1 (1-2) : 21-39, mar/set, 1970. 